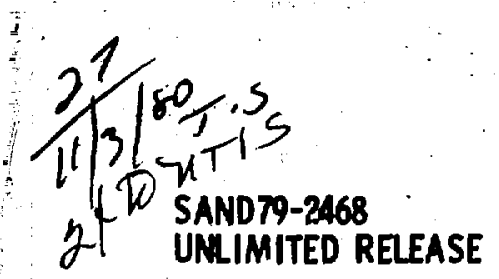

\title{
ASSESSMENT OF POTENTIAL RADIONUCLIDE TRANSPORT IN SITE-SPECIFIC GEOLOGIC FORMATIONS
}

\section{MUSTER}

R. G. DOSCH 


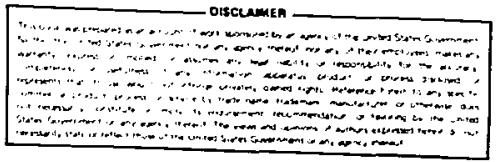

SAND79-2468

UNIIMITED DISTRIBUTION

Assessment of Potential Radjonuclide Transport in site-Specific Geologic Formations

R. G. Dosch

Chemical Technology Division 5812

Sandia National Laboratories

Albuquerque, New Mexico 87185

\section{ABSTRACT}

Associated with the development of deep, geologic repositories for nuclear waste isolation is a need for safety assessments of the potential for nuclide migration. Frequently usec in estimating migration rates is a parameter generally known as a distribution coefficient, $K_{d}$, which describes the distribution of a radionuclide between a solid (rock) and a liquid (groundwater) phase. This report is intended to emphasize that the use of $K_{d}$ must be coupled with a knowledge of the geology and release scenarios applicable to a repository. Selected $\mathrm{K}_{\mathrm{d}}$ values involving rock samples from and groundwater/brine simulants typical of two potential repository sites, WIPP and NTS, are used to illustrate this concern. Experimental parameters used in $\mathrm{K}_{\mathrm{d}}$ measurements including nuclide concentration, site sampling/rock composition, and liquid-to-solid ratios are discussed.

The solubility of U(VI) in WIPP brine/groundwater was addressed in order to assess the potential contribution of this phenomena to $K_{d}$ values. The results showed a general decrease in solubiiity with increasing $\mathrm{pH}$ as well as a dependence on the total amount of $U(V I)$ initially present in solution ( $1-50$ ppm range). Also indicated was the formation of a U(VI) particulate which passed an $0.8 \mu \mathrm{m}$ filter but was retained on a 0.2 um filter. This behavior was observed in a simulant with a composition based on brine from a halite zone in the vicinity of WIPP.

Understanding mechanisms of sorption of radionuclides on rocks would lead to a better predictive capability. In most instances, these are not clearly defined ard sorption is attributed to the presence of trace constituents (often unidentified) in rocks, i.e.. clay or hydrous oxide materials. An attempt was mace to determine if this applied to WIPP dolomite rocks by comparing sorption behavior of the natural material with that of 
a synthetic dolomite prepared in the laboratory with reagent grade chemicals. The results were inconclusive as $\mathrm{K}_{\mathrm{d}}$ values for $C_{s}, S r, E u$ and $P u$ were comparable or higher on the synthetic material.

The results of a study of TC sorption by an argillite sample from the Calico Hills formation at NTS under ambient laboratory conditions were more conclusive. The Tc sorption was found to be associated with elemental carbon, which comprised approximately 18 by weight of the rock. Available evidence points to a reduction mechanism leading to the apparent sorption of Tc on the solid phase. 
TABLF OF CONTENTS

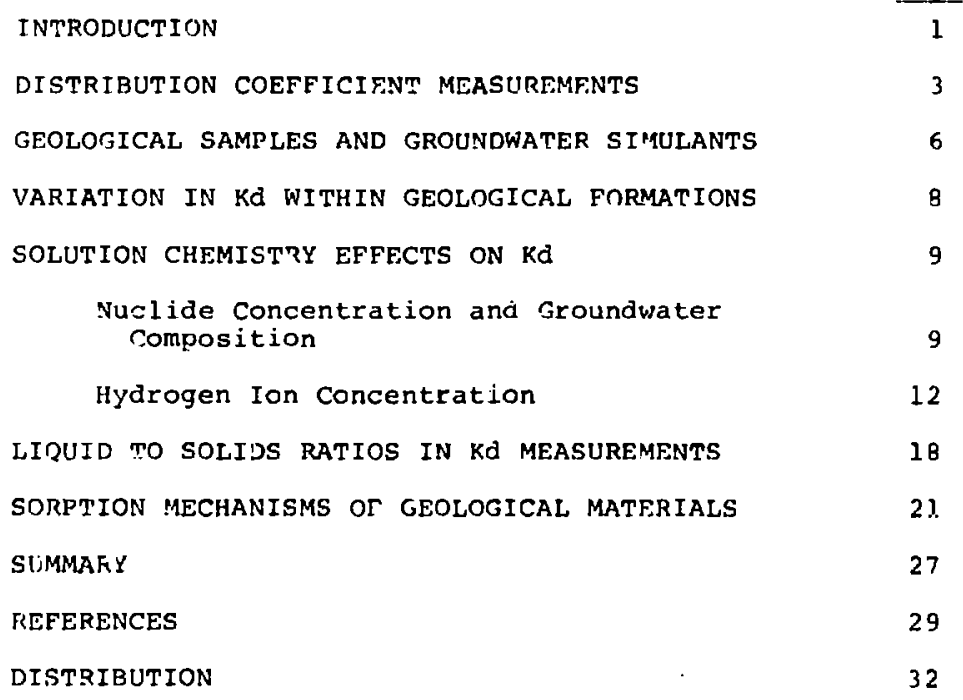

Page

1

9

9

12

18

21.

27

29

32 


\author{
SAND7 9-2468 \\ UNLIMITED DISTRIBUTION \\ Assessment of Potential Radionuclide Transport \\ in Site-Specific Geologic Formations \\ R. G. Dosch \\ Sandia National Laboratories \\ Albuquerque, New Mexico 87185
}

\title{
INTRODUCTION
}

Nuclear waste generated both in Defense Programs and in the commercial sector is currently being stored in surface facilities in the U. S. These facilities were not designed to provide isolation of long-lived nuclides from the bjosphere for long periods of time. Among the alternatives being considered is bermanent dispnsal in geologic formations located deep beneath the surface of the earth. The most probable scenario for radionuclide release from a deep geologic repository assumes an infusion of qroundwater into the repository, leaching of the solid waste therein, and subsecruent transport of the dissolved waste to surrounding geologic formations. Although site selection criteria may be designed to give an extremely low probability of occurrance to this scenario, the safety assessment for a specific site must include some evaluation of potential releases of radioactivity to the biosphere.

If groundwater containing dissolved radionuclides from the waste should enter the surrounding geologic formation, reactions such as sorption on rock surfaces or precipitation resulting from changes in solution chemistry can retard nuclide transport. The formation thus acts as a barrier to nuclide transport and. for 
sofety assessment, it is desirable to quantify this effect. Both site geology and hydrology are obviously very important in nuclide transport modeling. However, this paper deals only with the sorption phenomena.

Ideally, sorption measurements would be made in situ, at the fifld repository site. However, practical considerations dictate first abroximations be made from simple lahoratory mrasurements l..ing core samples and groundwater simulants which are representacive of site reology and hydrology. The measured parameter generally ropresenting sorption in transport models is the ristribution coefficient, Kr, which demotes the equilibrium list 2 hution of a qiven nuclide between a solid phase (rock) and a lauir phase (aroundwater), expressed in units of ml/gram. In measuring Kd's, solution-rock contacl times are generally baser? on the time necessary for the system to reach a constant distribution and can vary from hours to weeks (1). Sorption can and probahly does occur on more than one mineral phase in a given rock sample. precipitation or sorption onto container surfaces can also result in the loss of a nuclide from the liquid phase. In practice, reported $\mathrm{kd}$ values generally include all applicable sorption mechanisms and are in that sense empirical valies denoting a nuclide distribution valid only for a specific set of axperimental conditions. Nevertheless, the $k d$ represents the best available means of comparing the sorption properties of rocks from potential repositnry sites if the measurements are performed under identical conditions. The importanco of controlling these 
conditions is emphasized in the results of a study initiated by Relya and serne ( $\underline{2}$ ) in which eight laboratories were given "identical" rack samples and solution compositions to be used in measuring $\mathrm{Kd}$ for $\mathrm{Pu}, \mathrm{Sr}$, and $\mathrm{Cs}$. Dther parameters were left to the discretion of the partjcipants. Variations of two to three orders of magnitude in some of the reported kd values for a given nuclide and rock were attributed to the differences in the experimental procedures used.

In site-specific sorption studies, the choice of experimental parameters is narrowed by the availability of specific field information applicable to the site. This includes groundwater chemistr: and mineralogy of the rocks and variations that can be exrected to occur based on site characterization studies and reasonablc accident scenarios. In this paper, the influence of these parameters representing the environment and other more arbitrary experimental parameters, such as initial tracer concentration and solution-volume to rock-mass ratio, on sorption properties is discussed. Experimental results obtained in our laboratories anc. by others will be used to emohasize the fact that a discrete value in the form of a $\mathrm{Kd}$ assigned to a given radionuclide cannot adequately describe its interaction with a complex geolodic environment.

\section{DISTRIBUTION COEFFICIENT MEASUPEMENTS}

Experimental procedures used in determining kd generally fall into one of two general types: 1.) a static method represented by batch contact of monolithic or powdered rock with a liquid phase, and 2.) dynamic methods where the liquid phase 
flows through monolithic or aggregate rock columns. Both techniques are used in our laboratory; however, the static method using powdered rock is experimentally preferred for the majority of the work. The large number of measurements needed to evaluate the effects of various parameters on kd values are done more efficiently by the batch method in terms of time, laboratory space, and consumption of limited quantities of core sample. Once potential reactions have been characterized, a limited number of flow experiments must be performed to assess the effects of changes in sorption kinetics, surface area, and surface mineralogy which inay have resulted from grinding or olher size-reduction and homoqenizing techniciues. Rock samples used in the batch $x_{0}$ 's reported in this paper were prepared by reducing a representative section of a core sample to a: 74 "maximum-particle-dimension powder. This was accomplished by continued grinding or ball-milling in alumina or tungsten carbide apparatuses until the entire sample passed through a U.S. standard sieve with an average opening of $74 \mathrm{H}$. Liguid-to-solid ratios during batch contacting were in the range of 30 to $50 \mathrm{ml} / \mathrm{gram}$ unless otherwise noted. Radioisotones were added to groundwater simulants by air-drying the desired quantity of a stock solution of the tracer at ambient temperature in a borosilicate glass container contacting the residue with a groundwater simulant for a minimum period of one day, and then filtering the solution through a 0.8 wilter (Acropore from Gelman Instr. Corp., Ann Arbor, Michigan). This method was found to be more satisfactory than the direct addition of the stock solution as 
simulant $\mathrm{pH}$ was not altered and changes ir. "feed" solution activicies with time were minimized or 2 liminated. Simulants were traced with only one nuclide for any given measurement. All solutions were assumed to be initially in eauilibrium with the atmosphere and no attempt was made to control ih juring the: measurements.

Batch contacting was done in screw-ton polvethulene droduer bottles. Polyethylene film was placed over the bottle onening prior to replacing the top to prevent leakaqe. Sample bottles were agitated during contact times using a wrist-action shaber. Samples of the liquid phase were taken for analyses by wacin: an 2.8 . Filter (Acropor ${ }^{R}$ ) over the bottle opening, replarin: lhe dropiser cap, and compressing the bottle to force the lianll through the filter. The liauidfilter contact times were on the orier of 15-15 seconds, and no bias in results due to sorption of the radionucludes on the filter material was observed when the fitters were used in this masner.

Kd values were based on liquad-ohase analvses, i.c., sal: :phase activities were calculated from the difference in act: $\because 1 \%$ between a control sample and a sample of the liquid contacted with a rock. With the exception that control solutions were not contacted with rock, they were subjected to the same experimental conditions as were the sample solutions. Pu, An, and TC activities were determined by liquid scintillation using Packard Insta-Gel scintillation cocktail and a Packard sotel A3255 liquid scintillation counter. All other isotopes were analyrec by gamma spectroscopy using a $3 \times 3$ inch sodium iodide well detector with a Searle Model 1185 automatic gama counting system. 
GEOLOGICAL SAMPLES AND GROUNDNATER SIMULA!TTS

Rocks used included dolomites from the Los Medanos area in southeastern New Mexico (WIPP site) and argillaceous rock from the vevada Test site (NTS). Laboratory samples were taken Erom core samples obtained from boreholes in these areas. The dolomites, subsequently referred to as Magenta and Culebra, were from two water-bearing dolomite units, which are part of the Rustler Formation at the WIPF site, and overlie the repository horizon, which is deep in the salado Formation. The upper dolomite unit, Magenta, is a fine crystalline, dense dolomite and the lower, Culebra, is vuggy and commonly associated with anhydrite $(3,4)$. Hoth are approximately $20-30$ feet in thickness. Specific boreholes and depths from which samples vere taken are included in subsequent discussions.

Argillite was from the Fileana Formation at NTS. Laboratory samples were from the 1805-ft. level of Hole Ufile in the syncline Ridge area and the 1018-ft. level of Hole UF,25A *3 in the Calico Hills area ( 5 ).

Groundwater simulants used in work with the dolomites are referred to as solutions A, B, C and Culebra water. These compositions are given in Table $i$. A brief description of these simulants is as follows: 1) Solution A - a brine with high concentrations of $\mathrm{K}$ and $\mathrm{Mg}$ to simulate a solution formed by water in contact with potash deposits in the vicinity of the NIPP site, 2) Solution B - a brine used to simulate a solution formed by water flooding of the former lower repository horizon at WIPP, 
TABLE 1

Nominal Compositions of Groundwater/Brine simulants

\begin{tabular}{|c|c|c|c|c|c|}
\hline species: & Solueton $\Lambda$ & Solution B & Sosution C & Culebra $1_{2} \cap$ & $\because 4$ \\
\hline Na & 42,000 & 115,000 & 100 & 2.850 & $3^{n}$ \\
\hline к & 30,000 & 15 & 5 & 105 & 6.1 \\
\hline $\mathrm{Mg}$ & 35,000 & 10 & 200 & 140 & 25 \\
\hline $\mathrm{Ca}$ & 600 & 900 & 600 & 685 & 79 \\
\hline Fe & 2 & 2 & 1 & 0.07 & า. ก: \\
\hline$s r$ & 5 & 15 & 15 & - & 0.42 \\
\hline $\mathrm{Li}$ & 20 & - & $-\cdot$ & -- & -- \\
\hline $\mathrm{Pb}$ & 20 & 1 & ; & -- & $\therefore$ \\
\hline $\mathrm{Cs}$ & 1 & 1 & 1 & -- & $\ldots$ \\
\hline Mn & -- & - & - & 0.17 & - - \\
\hline$s+$ & -- & -- & - & 2.6 & 31 \\
\hline $\mathrm{Cl}$ & 190,000 & 175,000 & 200 & 3.750 &, 3 \\
\hline $\mathrm{Br}$ & 400 & 400 & -- & -- & -- \\
\hline$I$ & 10 & 10 & - & -- & $\cdots$ \\
\hline$F$ & -- & -- & -- & 1.3 & 1.1 \\
\hline $\mathrm{so}_{4}^{=}$ & 3.500 & 3,500 & 1,750 & 3,100 & 13 \\
\hline $\mathrm{B}\left(\mathrm{BO}_{3}=\right)$ & 1,200 & 10 & $=-$ & 9.8 & $\ldots$ \\
\hline $\mathrm{ICO}_{3}-$ & 700 & 10 & 100 & 59.5 & $24 n$ \\
\hline $\mathrm{NO}_{3}^{-}$ & $\cdot-$ & -- & 20 & 0.09 & -- \\
\hline $\mathrm{pH}$ & 6.5 & 6.5 & 7.5 & 7.5 & -.2 \\
\hline
\end{tabular}

*Al concentrations given in units of ma/liter. 
3) Solution $C$ - a simulant intended to represent potable groundwaters, used for agricultural purposes, from the dolonite units in the Los Medaños area, and 4) Culebra water - a simulant with a ccaposition based on the averaged compositions of non-potable brine found in the Culebra dolomite in bcreholes $\mathrm{H}-2 \mathrm{~b}$ and $\mathrm{H}-2 \mathrm{C}$ near the site $(\underline{6})$.

Groundwater simulant used with the argillite had a composition similar to water from Tippipah 1 imestone and uppermost quartzite in the Fleana Formation at NTS. The composition is given in Table 1 and the method of preparation of this simulant is described elsewhere (ㄱ)

VARIATION IN Kd WIMHIN GEOLOSICAI, FORMATIONS

The initial step in doing sorption studies related to a s:te-specific geologic formation is choosing samples to represent various rock units in the formation. Rock samples taken from various depths in a number of boreholes in the culebra and Magenta members were available for study in the form of 2-in. or 4 in. diameter cores approximately 6 in. in length. Powdered samples of these cores were contacted with Culebra water containing Cs. Sr, or Pu(IV) tracer at concentrations of $0.01 \mu \mathrm{Ci} / \mathrm{ml}$ and $\mathrm{Kd}$ values as a function of sample location are given in Table 2. These results were uxtracted from a larger body of data dealing with sorption properties in Magenta and Culebra ( $\underline{8}$ ) and represent the range of values observed for these particular nuclides.

Comparison of $\mathrm{Cs}, \mathrm{Sr}$, and $\mathrm{Pu}(\mathrm{IV}) \mathrm{Kd}$ 's on syncline Ridge and Calico Hills argillite showed variations of less than a factor 
of two for Cs and Sr, and less than an order of magnitude for Pu (9). However, Tc Kd's differed by more than an order of magnitude on the two materials, i.c., at Tc concentrations of $0.001 \mathrm{HCi} / \mathrm{ml}$, a $\mathrm{Kd}$ of $6.5 \times 10^{+3}$ was found for the calico $\mathrm{llills}$ argillite and 200 for the syncline Ridge material. The sorption of TC on the argillite from Calico Hills is discussed in more detail in a subsequent section concerned with sorption mechanisms.

\section{SOLUTION CHEMISTRY EFFECTS ON Kd}

\section{Nuclide Concentration and Groundwater Composj.tion}

Both groundwater composition and nuclite concentration are important parameters since many rocks exhibit low cation exchange capacity and non-linear sorption isotherms. Shiao, et al. (ID), in studies with montmorillonite clays, found kd values for $c s$, $\mathrm{Sr}$ and $\mathrm{Pu}$ decreased gradually with increasing nuclide concentration until a loading of approximately 208 of the total exchange capacitv of the clay was achievea. A more precipitous decrease followed at higher loading.

Similar behavior was noted in this work for Cs sorption from Solution $\mathrm{C}$ on Culebra dolomite and from NTS water on Syncline Ridge argillite (Fig. I). The sorption behavior of $\mathrm{Cs}$ on argillite may parallel the observation of Shaio as the material contained significant quantities of clay mirerals including approximately 5 volume percent of montmorillonite. The concentration range in which $k d$ is rapidly decreasing $\left(>10^{-4}\right.$ * $\left.\mathrm{cs}^{+}\right)$is probably unrealistically high in terms of concentrations which may be expected due to a repository failure anless natural Cs concentrations are high in the groundwaters. 
For Cs sorption on dolomite, the change in $\mathrm{Kd} \mathrm{(Fig.} \mathrm{1)} \mathrm{with}$ nuclide concentration is significant in a lower concentration range. The problem presented by this behavior in terms of current transport modeling lies in using a discrete value of $\mathrm{kd}$ to describe the sorption of Cs on Culebra dolomite; obviously this sorption isotherm is nonlinear. This purpose would be better served using empirical a partition ratio which is a function of nuclide concentration. Two such expressions derived to fit the

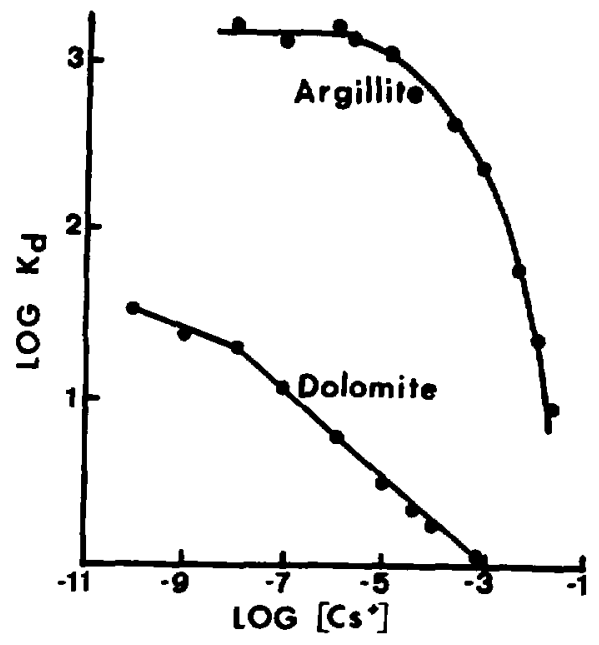

Figure 1. Distribution coefficients (Kd) for Cs on argillite from Syncline Ridge and Magenta dolomite are plotted as a function of the initial cs concentration in moles/liter. 
Cs sorption data in Figure 1 are $K^{\prime}=[\mathrm{Cs}]_{\mathrm{rock}^{\prime}}[\mathrm{Cs}]_{\mathrm{liquid}}^{87}$ and $\mathrm{K}^{\prime \prime}=[\mathrm{Cs}]_{\text {rock}} /[\mathrm{Cs}] \mathrm{ilquid}$ over initial Cs concentration ranges of $8.4 \times 10^{-11}$ to $8.4 \times 10^{-8} \mathrm{M}$ and $8.4 \times 10^{-8}$ to $7.5 \times 10^{-4} \mathrm{M}$, respectively. Average values of $1.5 \pm 0.1$ and $0.18 \pm 0.01$ were found for $K^{\prime}$ and $K^{\prime \prime}$, respectively.

The need for two empirical expressions to describe the sorption behavior of $\mathrm{Cs}$ on Culebra dolomite as a function of concentration is not understood. If the phenomena is related to exchange capacity, either a low capacity or sorption on a minor component of the dolomite is suggested. Another explanation may be that multiple mechanisms and/or minerals are involved in cs sorption. The latter was postulated by Erickson in explaining similar obsezvations for sorption of Cs on smectite-rich red clay from the North Pacific (11). Groundwater composition is of particular importance for repositories planned for halite formations, where any water exiting a repository would most likely be a saturated brine. Subsequent dilution in other groundwaters could result in widely varying compositions, particularly with respect to sodium content. A decrease in nuclide $\mathrm{Kd}$ 's with increasing sodium concentration is expected for ion exchange sorption mecranisms. Beall and coworkers (12) observed this trend in studying the sorption of Cs, $\mathrm{Rb}$, and the trivalent lanthanides/actinides on the clay minerals attapulgite, montmorillonite, and kaolinite as a function of sodium concentration.

Similar behavior was observed in our work for sorption of Cs on Magenta dolomite where $\mathrm{Kd}$ 's decreased from greater than 600 in deionized water to approximately 20 in simulants containing 
$5 \mathrm{M} \mathrm{Na}^{+}$concentrations. over a range of $0.25 \mathrm{M}$ to $5.0 \mathrm{M} \mathrm{Na}^{+}$ produced by the addition of varying amount of solution $B$ to Solution C, a fivenfold decrease in Cs kd was observed. Again, an empirical relationship, $K \cdots=K d$ iNal ${ }^{52}$, can be used to describe Cs sorption, in this case as a function of Na concentration. A value of $57 \pm 4$ was found for $\mathrm{K}$ '" over the sodium concentration range cited above.

\section{Hydrogen Ion Concentration}

The importance of groundwater $\mathrm{pH}$ in radionuclide transport is a $\because$ iffic!lt parameter to assess. Certainly, the pH plays an important role in determining the solubility and speciation of some of the radionucl: les. Tater exiting a repository with a pH substantially different than water in the surrounding geology may also alter the mineralogy of the rocks.

The nominal $\mathrm{PH}$ of WIPP solutions $A, B$, and $C$ were $6.5,6.5$, and 7.5 respectively, based on pli measurements of the waters on which the simulant concentrations were based. After contacting powdered $\mathrm{Cu}^{\prime}$ sa and Magenta dolomites, tyrical $\mathrm{pH}$ values of $6.9,7.6$, and, 2 are found for solutions $A, B$, and $C$, respectively. Neither the difference in $\mathrm{Ph}$ between the three solutions nor the $\mathrm{pH}$ changes which occurred during contact with dolumite could be simply correlated with observed kd values.

A simple procedure used in our work to look for potential $\mathrm{pH}$ effects involves consecutive Kd measurements made by contacting two samples of a given rock with the same liquid phase. Effects such as rock alteration, nuclide precipitation, or changes in nuclide species which may result from a $\mathrm{pH}$ change during the 
initial rock-solution contact should be evidenced by a change in observed Kd during a subaequent contact of the same liquid phase with a fregh sample of the same rock. Applicability of this test extends only to those nuclides which have a linear absorption isotherm j.n the concentration range involved.

The results of one such test for the sorption of pu(IV) in Solution B on Culebra dolomite are shown ir Table 3 . Dolomite samples were contacted with as-prepared solution $B$ (pH $=6.6$ ) and Solution $B$ which had been pre-equilibrated with powdered Culebra dolomite and filtered through an $0.9 \mu f i l t e r(\mathrm{pH}=7.8)$, woth of which contained approximately $1.4 \times 10^{-3}$ ppm of $238 \mathrm{Pu}$ (IV). The initial contact time was seven days, after which the solutions were filtered with $0.8 \mu$ filters and alalyzed. The filtrates were then contacted with fresh samples of cilebra dolomite for twelve days, filtered with $0.8 \mu$ filters, and analyzed. The overall agreement between the first and second $\mathrm{kd}$ values is considered to be good, particularly for the pre-equilibrated simulant. The difference in Kd's in the as-prepared simulant may be attributed to $\mathrm{pH}$ effects or changes in the system which resulted in $\mathrm{pH}$ changes; however deviations of this magnitude, less than a factor of two, are commonly observed in duplicate kd measurements.

Both pH and solution composition effects were apparent in a recently completed study on the interactior of U(VI) with Cilebra and Magenta dolomite, and argillite (13). As a part of this work, U(VI) solubility measurements were done in solutions $A$, B. and 
TABLE 2

Nuclide Sorption on Magenta and Culebra Frof. Variuus Boreholes/Depths at the lifp site

\begin{tabular}{|c|c|c|c|c|c|}
\hline \multirow{2}{*}{\multicolumn{2}{|c|}{ BoreholédDopth }} & \multicolumn{2}{|l|}{ Member } & \multicolumn{2}{|c|}{ (d. $m l_{1} g$ (1) } \\
\hline & & $\ldots$ & $\mathrm{Cs}$ & SE & Pu(IV) \\
\hline$A L C=8$ & $743^{1}$ & Maqento & 220 & 30 & 450 \\
\hline $15 \lambda$ & $818^{\circ}$ & Hagenta & 0.6 & 22 & 24 \\
\hline $114 \mathrm{~A}$ & $399^{\circ}$ & Muenta & 0,0 & 1.5 & 830 \\
\hline $114 \mathrm{~B}$ & 5174 & culebra & 9 & 0.6 & 200 \\
\hline$H+B$ & $52 r^{\circ}$ & Culebra & 1.2 & 32 & 80 \\
\hline 1158 & $900^{\circ}$ & Culebra & 26 & 0.3 & 390 \\
\hline
\end{tabular}

1) One gram samples of rock were contacted with $30 \mathrm{ml}$. cf solution for a period of two weeks.

TABLE 3

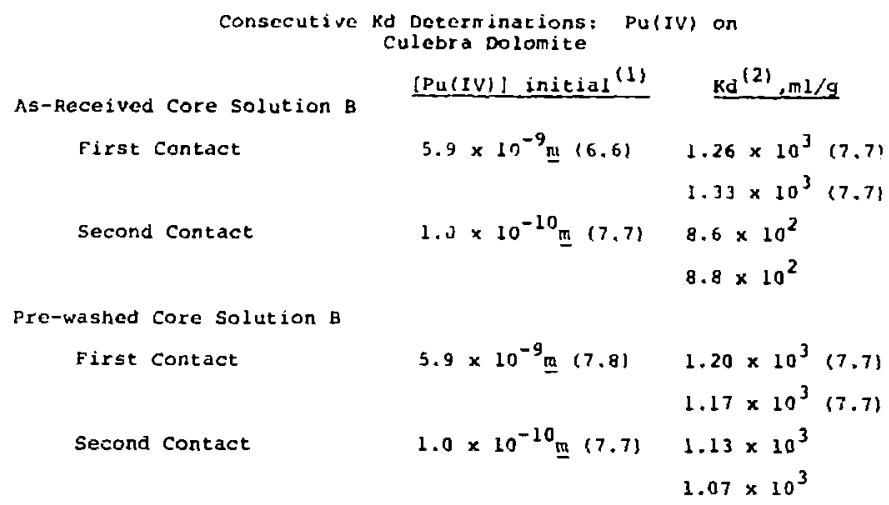

1. The $\mathrm{pH}$ of the PuiIV) - Solution B feed solutions are given in parentheses.

2. The results of duplicate experiments are listed. "Equilibrium"pH values are given in parentheses. 
$C$ as a function of $\mathrm{pH}$ and initial $\mathrm{U}$ (VI) concentration. The solutions initially contained 1,10 , or $50 \mathrm{ppm}$ of ${ }^{23 \theta} \mathrm{U}(\mathrm{VI})$ traced with ${ }^{237} \mathrm{U}(\mathrm{VI})$. Samples of each concentration were adjusted to a pl: of 7, 8, or 9. After five days, the $\mathrm{pH}$ was again measured and analytical samples were taken thru both $0.2 \mu$ and $0.8 \mu$ filters (Gelman Acropor ${ }^{R}$ ). A partial summary of the rcsults is aiver in Tables 4 and 5, however, the trends observed are applicable to ail the measurements.

Two potential sources of error, sorption on container and/or filter materials, were found to be negligible in this work. Variation in the final pH from the nominal values reflect changes which occurred during the five day equillbration period. The analytical results shon an expected decrease in U(VI) solubility with increasing $\mathrm{pH}$ and also point out the complexity of U(VI) solubility, which cannot be expressed by a simple solubility product. Solid precipitates were visually observed in only two samples, both containing solution $A$ at $10 \mathrm{ppm} U(V I)-p H 8.8$ and $50 \mathrm{ppm} U(V I)$ - pH 8.48, respectively. In both cases the quantity of solid was too great to be attributed solely to $U$ (VI) and most likely resulted from solution supersaturation during pH adjustment. However, some phenomena which occurred in Solutions $B$ and $C$, but not in $A$, resulted in the formation of $U(V I)$ species that couli be differentiated by $0.8 \mu$ and $0.2 \mu$ filters.

The results of $U(V I)$ kd measurements on Culebra dolomite in four simulants are given in Table 6 . Concentrations of $1.4 \mathrm{x}$ $10^{-3}$ ppm U(VI) comprised of a mixture of ${ }^{236} \mathrm{U}$ and ${ }^{237} \mathrm{U}$ were used in all of the measurements. 
TABLE 4

Concentration and pH Dependence of $U(V T)$ solubility in solution $A$

\begin{tabular}{|c|c|c|c|}
\hline $\left.\ln 2 L_{1} a\right]\left[\mathrm{C}\left(\mathrm{V}_{1}, \dot{L}, \mathrm{ugm}\right.\right.$ & fl1 21 & $\begin{array}{l}{[u(v i)] \text { in }} \\
0.2 \text { fiLes }\end{array}$ & $\begin{array}{c}\text { Filtrate, ppm } \\
\text { 0.Bu Eilter }\end{array}$ \\
\hline 50 & 7.1 & 49 & 50 \\
\hline 50 & 8.0 & 29 & 29 \\
\hline so & a. 5 & 1.3 & 1.1 \\
\hline 10 & 7.1 & 9.7 & 9.7 \\
\hline 10 & 7.9 & 4.9 & 4.7 \\
\hline 10 & 6.8 & 0.5 & 0.5 \\
\hline$!$ & 7.0 & 1.0 & 1.0 \\
\hline 1 & B. 0 & 0.0 & 0.7 \\
\hline 1 & B. 9 & c..? & 0.08 \\
\hline
\end{tabular}

TABLE 5

\begin{tabular}{|c|c|c|c|}
\hline Solution & Final ${ }^{2} H$ & 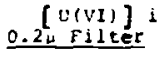 & $\begin{array}{l}\text { n Filtrate. Ppri } \\
\text { 0.,UFilter }\end{array}$ \\
\hline A & 7.1 & 9.7 & 9.7 \\
\hline A & 7.9 & 4.9 & 4.7 \\
\hline$\Lambda$ & B. 8 & 0.5 & 0.5 \\
\hline$B$ & 6.8 & 3.3 & 8.6 \\
\hline$B$ & $\therefore .4$ & 1.9 & 8.9 \\
\hline B & 8.8 & 0.4 & 5.0 \\
\hline c & 6.4 & 4.9 & 8.7 \\
\hline$c$ & 7.1 & 1.1 & 4.4 \\
\hline$c$ & 8.5 & 0.7 & 2.3 \\
\hline
\end{tabular}


Immediately apparent is the variation in Kd's with sample location reflecting mineralogi-variations and the dependence of Kd and, thus, potential U(VI) transport on the composition of the water. Kd's in the Culebra $\mathrm{H}_{2} \mathrm{O}$ simulant and Solution $\mathrm{A}$ are, in general, much lower than those observed in Solution B, a halite brine, and in the groundwater simulant $c$. The pH values are fair: consistent for a given solution, hut variations of greater than one $\mathrm{pH}$ urit are seen for different solitions. There appears to be little correlation between !R and s's solutions with the hiqhest and lowest average $\mathrm{pH}$, Culebra $\mathrm{H}_{2} \mathrm{O}$ and Solution $A$, both exhibit "u values lower than $B$ and $C$, which have intermediate sh values.

The formation of $V(V I)$ spesies in Solutions $B$ and $C$ which were differentiated by $0.2 \mu$ and $0.8 \mu$ filters in the solubility studies does not appear to be a factor in the kd values. Filters with $0.8 \mu$ pore size were used for liquid solid phase separations, yet the $K d$ values were generally higher in solutions $B$ and $C$ than those observed in $A$. Either the species Jid not form or formed more slowly at the lower U(VI) concentration, or it was absorbed or influenced in some other manner by the dolomite interacting with the solutions in a differeat manner. The general trend toward decreasing $\mathrm{Kd}$ in Solutions $\mathrm{g}$ and $C$ setween the four day and seven day measurements (also observed for lagenta dolomite) may be due to a slow change in $U(V T)$ speciction. The lower Kd values observed in solution $A$ as compared to $B$ and $C$ could result from the higher "g concentration in $A$ which could reduce the number of potential sorption sites available to I(VI) ion. There is no apparent explanation for the low values 
in the cluebra water, which has a composition bounded by those of " ution and solution $C$, but havina a $n H$ equivalent to solution C initially.

\section{LIQUID TO SOLIDS RATIOS IN Kd MEASUREMENTS}

The liquid-to-solid ratio used in measuring Kd by the batch contact method has been shown to affact the experimental results under some conditions. Due to practical considerations,such as the need for liquid/solid separation prior to analyses and the the limited availability of core sample, the tendency is to ise ratios (10ml/g) which are much higher than those found in typjcal geologic environments $(\cdot 1 \mathrm{ml} / \mathrm{g})$. An example of the influence of this ratio on the sor,tion of U(VI) on ragenta, culebra, and argillite from Calico Hills is shown in Table 7 .

The liquid phase used for the dolomite rocks was soluticn $C$ doped with $8 \times 10^{-10} \mathrm{MU}(\mathrm{VI})$ and that used for the argillite was the NTS simulant containing the same U(VI) concentration. Both solutions were traced with ${ }^{237}$ L(VI). The Magenta and Culebra dolomites were from the $749^{\circ}$ depth of AEC $\| 8$ borehole and the $900^{\prime}$ depth of the $45 B$ borehole, respectively. Two sets of experiments were done with the dolomites using powders of as-received dry core material and the same material which had been pre-washed three times with Solution C prior to contact with Solution C containi ' $g$ $U(V I)$. This was done by contacting the rock with solution $c$ using the same liquid-to-solid ratio used in the kd measurement, centrifuging, and decanting of the liquid. Liquid phase U(VI) concentrasions were determined by gamma spectroscopy using the $208 \mathrm{keV}$ peak of ${ }^{237} \mathrm{U}(\mathrm{VI})$ tracer. 
A significant trend of decreasing kd with decreasing liquidto-solid ratios was observed in all the dolomite measurements. The generally higher Kd's observed on the pre-washed dolomite may reflect a lower solution ionic strength due to removal of highly soluble components of the core sample durina the pre-wash step or possibly changes in the dolomite rock. In these samples there is no apparent correlation of $\mathrm{Yd}$ with $\mathrm{PH}$ as these values ather remain constant or increase slightly as the liguid-tosolid ratio decreases. Increasina in generally associated with Inureasing rather than decreasing sorption of cations on inorgunic materials (14). The results suggest that li(VI) sorition on lolnmite is governtd by a solubility sroduct relationship rather than an ion exchange equilibrium.

The trend toward decreasing U(VI) sorption on dolomite as field conditions are approached raises questions as to tie validity of extrapolating laboratory data to fieid conditions. However, the U(VI) results cannot be arbitrarily applied to the sorption if other radionuclides on dolomites. For example, Kd's determined in batch contact experiments with liguid-to-solid ratios in the range of 50 to $100 \mathrm{ml} / \mathrm{g}$ have been idecuate to predict Cs transport velocities through one-inch thicknesses of monolithic Magenta core (15), where the liquid-to-solid ratio of the saturated core is approximately $0.15 \mathrm{ml} / \mathrm{g}$.

similar constraints in generalizing the effect of liquid-tosolid ratios must be applied to arqillites. The results in Table 7 indicate that $U(V I)$ sorption on Calico Hills material is not dependent on the liquid-to-solid ratio. Hor ever, ${ }^{99}$ TC 


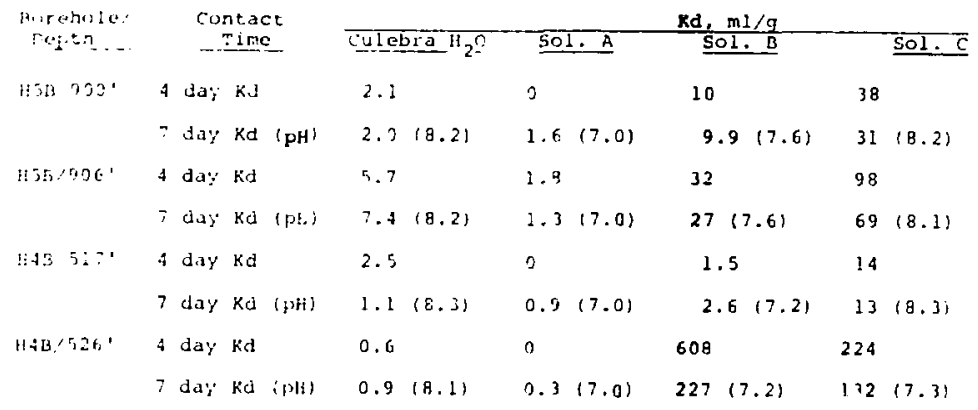

The Effect of Liquid To Sulid Ratbos on Distribution. Coefficients For U(VI) on Dolomites And Argillite and For $\mathrm{TCO}_{4}^{-}$on Argillite*

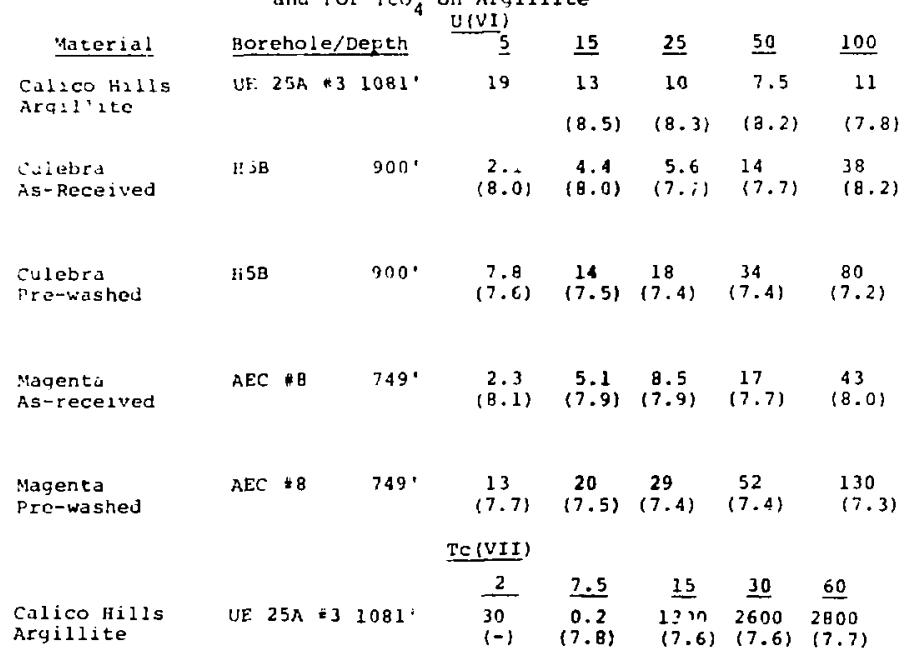

the $\mathrm{K}_{\mathrm{d}}$ values are given in units of $\mathrm{ml}, \mathrm{g}$. The values under the $\mathrm{K}_{\mathrm{d}}$ in parentheses are the Einal $\mathrm{pH}$ values. The underlined values at the top are liquid to solid ratios in units of $\mathrm{ml} / \mathrm{g}$. 
Kd values determined with the same material and simulant decreased significantly over a range of 1 iquid-to-solid ratios of 60 to $2 \mathrm{ml} / \mathrm{g}$ (Table 7).

\section{SORPTION MECHANISMS OF GEOLOGICAL MATERIALS}

Ideally, site-specific sorption studies would include investigations into riechanisms which lesult in the sor $\mathrm{p}^{+}$ion of a given ruclide or group of nuclides (i.e. trivalent lanthanides and actinides) on a rock. Many studies have beel devoted to ion exchange mechanisms leading to sorption on natural materials such as soils, clay minerals, and 7.æolites (16). However, information concerning sorption mechanisms associated with deep geologic environments is sparse, a condition which probably reflects a relatively recent interest in these phenomena. The wide variations in nuclide sorption properties of geologic materials which can be described by identical generic nomenclature points out the need for information of this kind. A knowledge of sorption mechanisms would lead to much greater certainty in predicting the influence of repository-related parameters such as those discussed above on potential radionuclide migration. In this section, the results to date of sorption mechanism studies on dolomites from the UIPP site and argillite from calico Hills are summarized. The purpuse for including these is to point out some of the problems assuciated with determining mechanisms (dolomite sorption) and the potential benefits of these studies (TC sorption on argillite).

The variability of the sorption results on natural dolomite suggests that sorption may be associated in part with minor or 
trace mineral phases in the dolomite. Heterogeneity in dolomite sorption properties was demonstrated by autoradiography of monolithic core samples which had been contacted with solutions containing tracer level concentrations (< $10^{-6} \mathrm{M}$ ) of nuclides (17) and in electron microprobe examinations of core sample which had been contacted with concentrated solutions ( $\geq 0.05 \mathrm{M})$ of stable isotopes of some of the fission product elements (18). Prior to trying to isolate "impurities" associated with heterogeneous sorptior on Magenta and Culebra, an attempt was made to determine the sorption properties of the dolonite matrix. Chemically pure, synthetic dolomite (protodolomite) was prepared from reagent-grade chemicals using the method of faines (19). Two separate syntheses resulted in materials shown to be a mixture of protodolomite and brucite, $\mathrm{Mg}(\mathrm{OH})_{2}$, and protodolomite, respectively, by comparison of their $x$-ray diffraction patterns with previously published data $(20,21)$. Distribution coefficients for several nuclides on the synthesized materials are compared with those measured on a natural dolomite in Table 8 . The results show that the overall sorption properties of the natural and synthetic materials are similar, indicating that the dolomite matrix of Culebra and Magenta can contribute to nuclide sorption.

There is an apparent disparity between these results and the autoradiography and microprobe data which indicate heterogeneous sorption. A possible explanation may be that impurities such as clay minerals (tentatively identified by microprobe data) in the natural dolomites tend to concentrate the nuclides as a result of higher exchange capacities rather than higher affinities for the 
nuclides. This could lead to an erroneous conclusion that nuclide sorption is associated only with impurities in the dolomite. The combined microprobe, autoradiography, and protodolomite experiments definitely lead to the conclusion that nuclide sorption on natural dolomite cannot be attributed to a single mineral phase, but occurs on at least two different phases (possibly by different mechanisms) and possibly more depending on the number and character of the trace constituents present.

The results of a study of the mechanism of Tc sorption on argillite from Calico Hills were more definitive, as jorption was found to be associated with a minor ( $\leq 18)$ carbon phase in the material. Technetium, present in sulution as the oxyanion, $\mathrm{TcO}_{4}^{-}$, under oxidizing conditions, has shown little tendency to sorb on deep geologic materials (22). Bondietti and Francis (23) observed apparent absorption of Ic on irneous rocks under reducing conditions which they attributed to a reduction of $\mathrm{TcO}_{4}^{-}$to form the sparingly soluble oxide, $\mathrm{TCO}_{2} \cdot$ Fried and co-workers observed absorption $0^{=}$up to $99+8$ of $\mathrm{TCO}_{\overline{4}}$ tracer on various sulfide minerals, a result which they suggested may be due to redox reactions and/or formation of insoluble sulfide compounds. The high. Kd values for TC on argillite from Calico Hills were observed under oxidizing $\mathrm{Eh}$ in our work and prompted an investigation into the mechanism involved. The results of the work are described below and summarized in Table 9 .

The as-received core sample contained $1.35 \% \mathrm{C}$ (organic), $0.032 \% \mathrm{~S}$, and ferrous iron in the form of siderite in the range of 1-108 by weight. These constituents were of interest because 
Radionuclido Sorption Propertie of Natural Dolomite and synthotic Protodolomite

Prata-dolomite $\mathrm{K}_{\mathrm{d}} \mathrm{ml} \mathrm{g}$ Natural dolomite $\mathrm{K}_{\mathrm{d}} \mathrm{ml} / \mathrm{q}$
Prep $1 \mathrm{l}$ Culebra

Cs 25

76

Sr $\quad 16$

9

E. $5 \times 10^{4}$

$4 \times 10^{5}$

9

4

Pu $\quad 5 \times 10^{3}$

$2 \times 10^{3}$

Tc

0

0

\section{5}

$1 \times 10^{4}$

$7 \times 10^{3}$

1

5

$1 \times 10^{4}$

$2 \times 10^{3}$

1.5

- XRD Patterng Showed Mixture of Protodolomite and Brucite.

- XRD patterns showed only I totodolomite

\section{TABLE 9}

Technet+um - 99 Sorption on Calico Hill Argillite ins-received Core
Kd, mlig
c, \& by weight
S, by weicht

HE $25 A$ A 1081 .

$2.6 \times 10^{3}$

1. 35

0.032

Initial Dissolution

(. 908 Total Weight Loss)

\begin{tabular}{cccc}
$\mathrm{HF}$ & $4.3 \times 10^{4}$ & 6.8 & 0.24 \\
$\mathrm{~F}+\mathrm{HNO}_{3}$ & 24 & 4.2 & 0.17 \\
& & \\
\hline Dotal Height Loss) & & \\
\hline$\left(\mathrm{HCl}+\mathrm{H}_{3} \mathrm{BO}_{3}\right)^{(1)} \mathrm{B} .5 \times 10^{4}$ & -98 & $\mathrm{ND}$
\end{tabular}

\footnotetext{
1) Residue Erom initial HF dissalution contacted with $\mathrm{HCl}+\mathrm{H}_{3} \mathrm{BO}_{3}$ solution

2) S and Hydrscarbons not detected by GC/MS analysis.
} 


\section{they represent potential reducing agents or precipitants}

for $\mathrm{Tr}$.

Samples of the core were contacted with $\mathrm{HF}$ o: $\mathrm{HF}-\mathrm{HNO}_{3}$ solutions at $70^{\circ} \mathrm{C}$ which resulted in dissolution of approximately 908 of the material. x-ray diffraction analyses showed the residues to be primarily (K, Na) $\mathrm{MgAlF}_{6}$, a compound which formed during dissolution as it was not observed in the as-received core. Emission spectrographic analyses showed only trace amounts (0-18 by weight) of iron remaining in the residues. Both dissolution techniques resulted in the loss of some of the organic carbo:., an effect that was greater in the HE-HNO ${ }_{3}$ solution as would be expected due to the presence of the oxidizing acid. The increase in $S$ content in the HF residue correlated with weight loss, however, the $\mathrm{HF}^{-\mathrm{HNO}_{3}}$ dissolution resulted in the loss of some of the $S$, again due to oxidation. Hydrocarbons were not detected in the residues by infrared spectroscopy or gas chromatography/mass spectrometry.

The most obvious difference in the residues was in their Tc sorption properties. The $K d$ of the HF residue for TC correlated reasonably well with the observed weight loss while the TC sorption properties of the $\mathrm{HF}^{-\mathrm{HNO}_{3}}$ mixture caused a greater decrease in the Kd for TC thain was observed under the same time and temperature conditions for $\mathrm{H}_{2} \mathrm{O}_{2}$ solutions $(\mathrm{Kd}=80)$ and aqua regia ( $\mathrm{Kd}=1.5 \times 10^{3}$ ). No effect on TC Kd was observed as a result of contacting the argillite with $\mathrm{HCl}$, either as a $1: 1$ $\mathrm{HCl}$ solution or in combination with HF. 
Contact of the HF residue with a $\mathrm{HCl}-\mathrm{H}_{3} \mathrm{BO}_{3}$ solution resulted in further dissolution leaving a residue which represented approximately 18 by weight of the original argillite sample. The Tc Kd of this residue again increased, however, not by an order of magnitude as would be expocted based on weight loss alone. $x$-ray diffraction, infrared spectroscopy, and gas chromatographic/ mass spectrographic analyses did not detect the presence of crystalline material, hydrocarbons, or sulfur. The residue was identified as carbon containing less than 2 non-volatile material when heated in air at $600^{\circ} \mathrm{C}$.

The study led to the conclusiol that TC sorption on argillite from calico Hills under oxidizing conditions was asmoclated vith a relatively pure carbon fraction comprising 18 by weight of the core sample. The use of activated carbon to sorb Tc has been reported (25), and tests in our laboratory with activated carbon materials from three sources (Barnebey-Cheney Co., Columbus, Ohio; Mallinkrodt Co., St. Louis Mo., and Matheson, Coleman and Bell, Cincinnati, Ohio) showed Tc kd's of $170,7.6 \times 10^{3}$, and $6 \times 10^{3}$ under the same conditions used in the argillice study. The chemistry involved in the sorption of $\mathrm{TcO}_{4}^{-}$on the "argillite carbon" has not been determined. The results of Landa and co-workers (26) who attributed Tc sorption observed on soil samples to living and/or non-living organic fractions in the soil and steigman and co-workers (27) who observed reduction of $\mathrm{TCO}_{4}^{-}$in dilute alkaline solutions in the presence of polyhydric alcohols and polyhydroxy acids suggest a reduction reaction involving active groups on the carbon surface. The 
significant decrease in Tc sorption or argillite subjected to the strongly oxidizing environmente of hot $\mathrm{HNO}_{3}$ and $\mathrm{H}_{2} \mathrm{O}_{2}$ solutions also suggests a reduction reaction. Electrochemical and ESCA studies being conducted in an attempt to resolve the mechanism have not been completed, but initial results point toward a reduction mechanism.

\section{SUMMARY}

The results presented in this paper are intended to reinforce a general observation of a number of investigators working in the area of nuclide transport in geologic environments. That is, a discrete value, such as a distribution coefficient, cannot be assigned to a given radionuclite to adequately describe its interacton with a specific rock type. Empirical relationships may be derived to account for chemical solution parameters such as nuclide concentration or groundwater composition. Parameters which are arbitrarily chosen for laboratory measurements, such as liquid-to-solid ratios and rock form (powder or monoliths) can be evaluated in terms of their importance for a given rock/ Fluid system and/or nuclide and minimized by subsequent experiment design.

Perhaps the most difficult unknown to account for in sitespecific nuclide transport studies is heterogeneity in a geologic formation. Differences in sorption properties among samples from different areas and depths of members, such as the Culebra and Magenta, are as large or larger than those which can be induced by orders-of-magnitude variation in other sorption phenomena. In lieu of in situ transport measulements involving 
representative samples of a geologic unit, which are very difficult in terms of accessibility, cost, and experimental duration, there would appear to be two other general approaches to overcoming the problem of heterogeneity.

The first would involve exhaustive site-specific sampling coupled with laboratory studies to determine nuclide sorption: properties to gain an understanding of the mechanisxs involved. The migration of $T c$ in argillite, for example, should be a workable problem given that retardation is probably related to a minor carbon phase in the rock and that the distribution of this phase and the hydrology, particularly with respect to oxidation reactions, of the environment could be characterized. The second approach would involve a change in emphasis from far-field studies to studies of near-field geology and engineered barriers designed to prevent or significantly delay the movement of any aqueous-borne nuclides from the repository environment into the surrounding geology. This would reduce the scope of site-specific transport studies to a well defined regime which are more apt to be adequately characterized with current technology and resources. Far-field migration studies associated with a repository site should not be ignored, but could be deferred until such time that existing or new technology can be applied to the purpose of characterizing deep geologic environments. 


\section{REFERENCES}

i. Seitz, M. G., Rickert, P. G., Fried, S. M., Friedman, A. M., and Steindler, M. S. "Studies of Nuclear-Waste Migration in Geologic Media", ANL-78-8, March 1978.

2. Relyea, J. F., and Serne, R. J., "Controlled Sample Program Number 2: Inter-laboratory Comparison o: Batch kd Values", PNL-2872, June 1979.

3. Lambert, S, J. and Mercer, S. $h .$, "Hydrologic Investigations of the Los Medanos Area, Southeastern New Mexico, 1977". SAND77-1401, January 1978.

4. Dosch, R. G, and Lynch, A. W., "Interaction of Radionuclides With Geomedia Associated lith the WIPP Site in New Mexico", SAND78-0297, June 1978.

5. Lappin, A. R, and Olsson, W. A., "Material Properties of Eleana Arqillite -- Extrapolation to other Arqillaceous Rocks and Implications for Waste Management", Proceedings of NEA/OCED Workshop on Utilization of Argillaceous Material for Isolation of Nuclear Waste", Paris, France, Sept. 10-12, 1979. In Press.

6. Geologic Characterization Report, WIPP Site, Southeastern New Mexico, edited by Powers, D. W., Lambert, S. J., Shaffer, S. E., Hill, I. R., and Weart, D. W., SAND78-1596, 1978.

7. Dosch, R. G., and Lynch, A. W., "Interaction of Radionuclides with Arqillite from the Eleana Formation on the Nevada Test Site", SAND78-0893, February 1979.

8. Dosch, R. L. and Lynch, A. W., To be published as a SAND report.

9. Lynch, A. W, and Dosch, R. G., "Interaction of Radionuclides with Geomedia From the Nevada Test site," to be published in proceedings of symposium on The Science of Nuclear Waste Management, Materials Research Society Annual Meeting, Boston, Mass., Nov. 26 - 30, 1979.

10. Shaio, S. Y., Rafferty P., and Mercer, R. E., "Ion Exchange Equilibria Between Montmorillonite and Solutions of Moderateto-High Ionic Strength", Radioactive Waste in Geologic Storage, Chanter 17, ACS Symposium Series 100, S. Fried, Ed., Sept. 1978. 
1.1. Erickson, K. L., "Radionuclide Sorption Studies on Abyssal Red Clays", Radioactive Waste in Geologic Storage, Chapter 15, ACS symposium Series 100, S. Friec, Ed., Sept. 1978.

12. Beall, G. W., Ketelle, B. H., Haize, R. G., and D'Relli:y, r. D. "Scrption Behavior of Trivalent Actinides and Rare Earths on Clay Minerals", Radioactive waste in Geologic storage, Chan. 12, ACS Symposium Series 100, S. Fried, Fd., Sept. 1978.

13. Dosch, R. G., to be published as a SAND report.

14. Amphlett, C. G., "Inorqanic Ion Exchangers", Elsevier Dublisting Company, Amsterdam, 1964.

15. Lynch, A. W. and Dosch, P. r., ":1iqration of Cesium in Dolomites from the Lns Medanos Mrea in Southeastern New Mexico," Annual Meeting of the American Nucl sar Society, Atlanta, Georgia, Tune $3-B, 1979$.

1(. Np's, J. A., Lucas, S., liathur, A. K., Phillifs, S. L., and rsao, C., "Theoretical and Experimental Evaluation of baste Transport in Selected Rocks", 1977 Annual Report of the LDL Contract No. $45901 \mathrm{AK}$, Waste Isolation Safety Assessment Proyram Collection and Generation of Transport Data. Suptember 1977.

17. Lynch, $A$. $: \mathrm{v} .$, Sandia Laboratories, Albuquerque, New Mexico, unpublished results.

18. Hiskebein, T. E. and Hlava, P. F., "Microstructural Interactions of Geologic Media With Waste Radionuclides", SAND780108 , March, 1978 .

19. Gaines, A. M., "Protodolomite synthesis at $100^{\circ} \mathrm{C}$ and AtmospheriC Pressure", Science, Vol. 183, P. 518, 1974.

20. Baron, G., "The Synthesis of Dolomite. Application to the Phenomenon of Dolomitization", Rev. Inst. Fr. Petrole, Vol. 15, P. $3-68,1960$.

21. Siegel, F. R., "Factors Influencing the Precipitation of Dolomitic Carbonates", State Geological Survey of kansas, Bulietin 152, 1961 Reports of Studies, Part 5, pp. 127 - 158, December, 1961 .

22. "Alternatives for Managing Wastes from Reactors and Post-Fission Operations in the LWR Fuel Cycles", ERDA. Publ. $76-43$, 1976. Vol. 4 . 
23. Bondietti, E. A., and Francis, C. W., "Geologic Migration Potentials of Tc-99 and Np-237". Science, Vol. 203, p 1337. 1979.

24. Fried, S., Friedman, A. M., Cohen, D., Hines, S. 5., and Strickert, R. G., "The Migration of Long-Lived Radioactive Processing wastes in Selected Rocks", Annual Report to the office of Waste Handling Project, AN 0115A, ANL-78-46, April, 1978.

25. Akatsu, E., Ono, R., Tsuruechi, K., and Uchiyama, H., "Radiochemical Study of Adscirption Behavior of Inorganic Ions of 2 irconium Phosplate, Silica Gel and Charcoal", J. of Nucl. S.i. and Tech., Vol. 2, No. 4, pp. 141-148, April, 1965.

26. Landa, E. R., Thorvio, L., and Gast, R. G., "Effect of Selective Dissolution, Electzolyses, Aeration, and Sterilization on Tschnetium-99 Sorption by Solls", E. Environ. Qual., Vol. 6 , No. $2,15: 7$.

27. Steigman, J., liwang. L., and Stivastava, S., "Complexes of Reluced Te-99 with Polyhydric Compouncls". S. Label CR Vol. 13. No. 12,1977 . 
U.S. Deportment of Energy, Headquarter: office of Nuclear Waste Monegement

Washington, DC 20545

Eugene F. Beckett, Project Coordinator (WrPP) (1)

Colin A. Heath, Director, Division of Waste Inolation (2)

Sheldon Meyera

ITeak II!

Raymond G. Ronatowski TTask II I

R. Stein

Carl L. Cooley

ITask II!

ITask II I

U.S. Department of Energy, Albuquerque Operations

P.0. Box 5400

Albuquerque, Nm 87185

D. T. Schueler, Marieger, inpp Project office (2)

G. Dennis, Director, Public Affairs Division

S. C. Taylor, CsTI Division (for Public Reading Roons)

U.S. Departuent of Energy

Carlsbad WIPP Project office

Room 113, Federal Building

Carlsbad, WM 88220

U.S. Department of Energy

cio Battelle

Office of Nuclear Waste Isolation

505 King Avenue

Columbus, OH 1320:

Jeff 0 . Neff

Battelle Memorial Institute

Office of Nuclear Waste Isolation

$505 \mathrm{King}$ Avenue

Columbus, OH 43201

Neil Carter, General Manager (3)

R. Heineman ITask II!

Wayne Carbiener ITask III

P. Hoffman

J. Kircher

G. Raines

Westinghouse Electric Corporation

P.O. Box 40039

Albuquerque, NM 87196

R. C. Mairson

Woodward-Clyde Consul tants !"!

Library Western Region

3 Embarcadero Center, Suite 700

San Francisco, Ca 94111

anne T. Barrigan, Librarian 


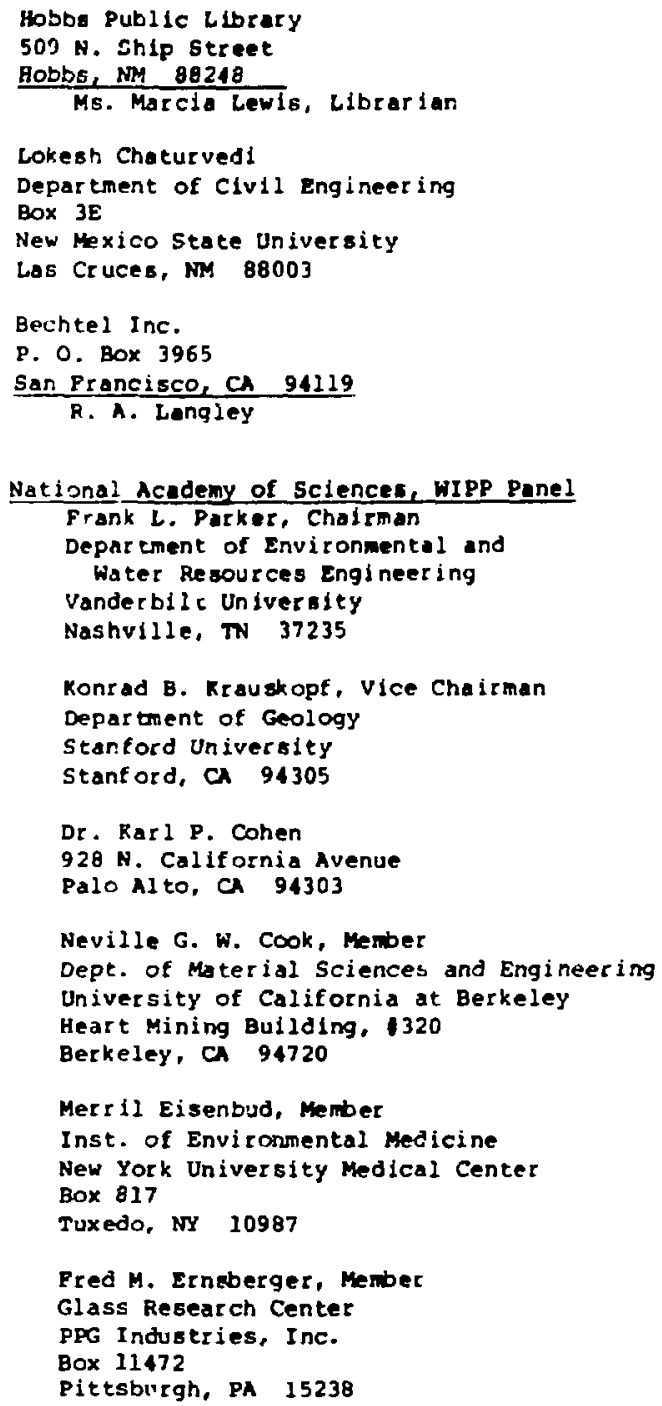




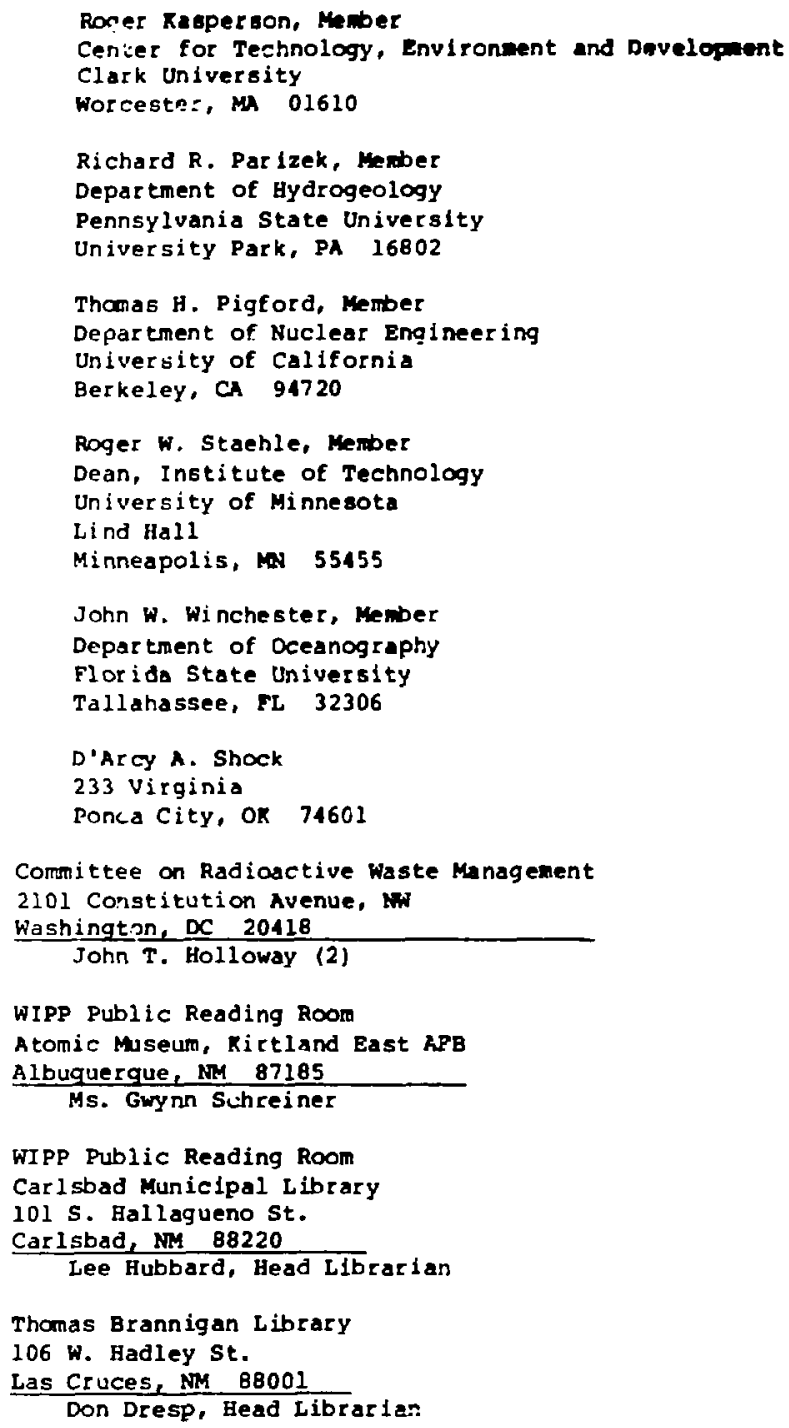




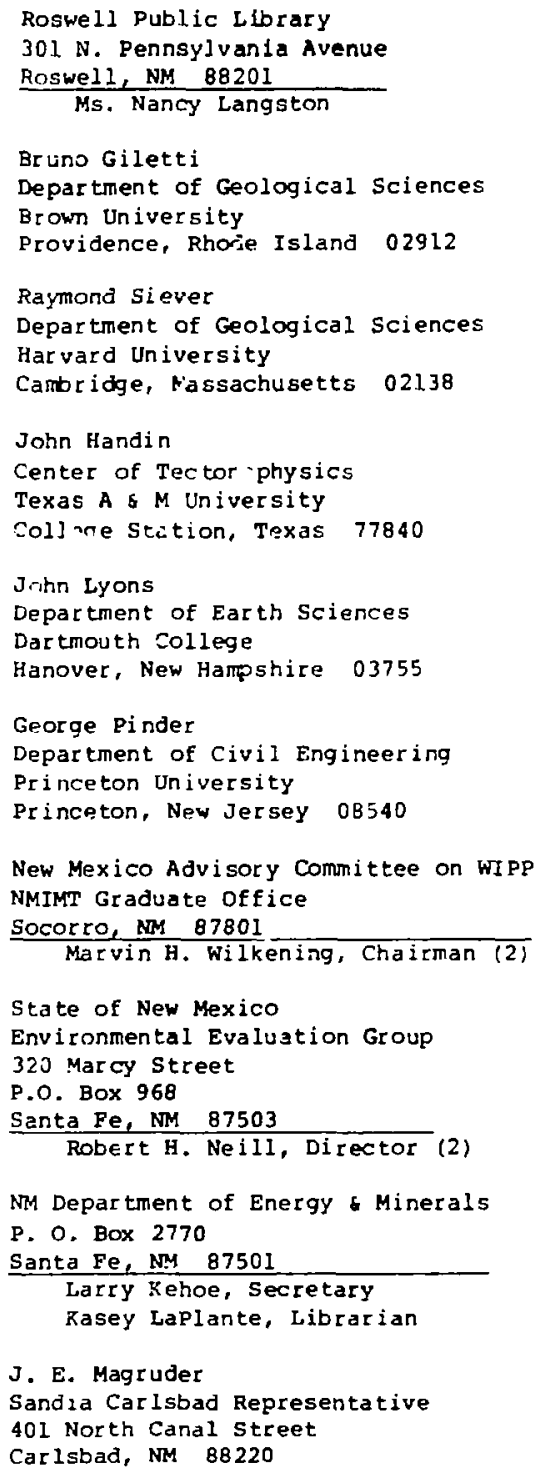


Brookhaven National Laboratory

Associated Univeraltien, Inc.

Upton, Long Ieland, Hew York 11173

Cal Brewster, BIdg. 830

Paul w. Levy, Physice Dept.

Brookhaven National Laboratoryl $+d$

Department of Applied sciences

Upton, NY 11973

P. Colombo

R. M. Nielmon

Mr. Michael J. Salthl +l

Rockwell International

Atomics International Divinion

Rockwell Banford Operation.

P. O. BOX 800

Richland, Wh 99352

The Pennoylvania state Univeralty $1 * 1$

Materials Research Laboratory

University Park, PR 16802

Dr. Della Roy

University of New Maxicoll

Geology Department

Albuquerque, $\mathrm{MM} \quad 87131$

D. G. Brooking

IArgonne National Inboratory| $*+1$

9700 South Cass Avenue

Argonne, IL 60439

II! S. Fried

III A. M. Friedman

Battelle Pacific Northwest Laboratories

Battelle Boulevard

Richland, WA 99352

R. J. Serne

J. Relyea

Los Alamos Scientific Laboratory

Los Alamos, NM 87545

T. K. Keenan, $\mathrm{H}-7$

B. Erdal, CNC-1l 


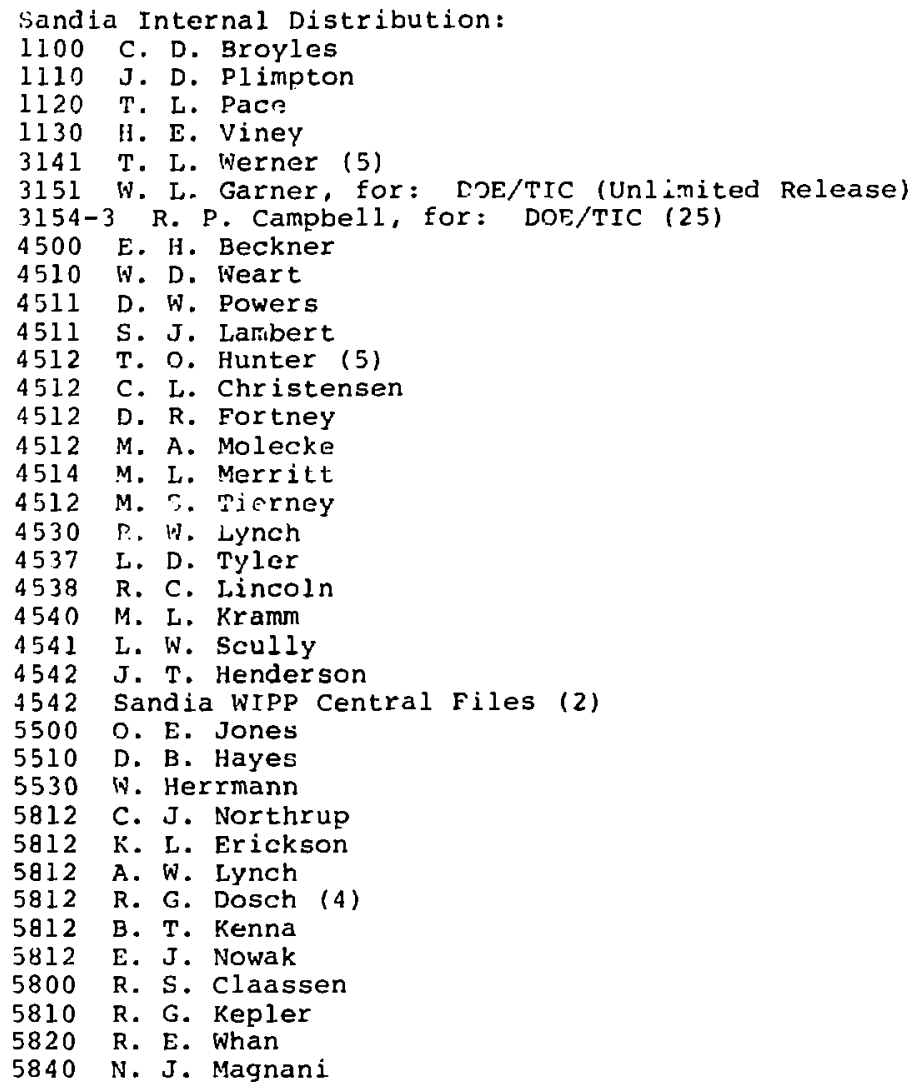

